\title{
EL PAPEL DE LA UNIÓN EUROPEA EN LAS NEGOCIACIONES SOBRE EL CAMBIO CLIMÁTICO
}

\author{
Xira Ruiz ${ }^{1}$ \\ UNISCI / Universidad Complutense de Madrid
}

\begin{abstract}
Resumen:
El trabajo analiza la postura de la Unión Europea ante el cambio climático, así como sus principales instrumentos de cooperación medioambiental en el sur del Mediterráneo. Se analizan los compromisos que ha adquirido la Unión en las distintas conferencias de las partes (COPs), su nivel de cumplimiento y su capacidad de liderazgo en el área del cambio climático desde la Cumbre de Río en 1992. También se examinan los principales compromisos adquiridos en las últimas conferencias de las partes y la postura de los actores clave ante la COP de París que se celebrará a finales de 2015. En la última parte, se profundiza en el impacto de iniciativas de cooperación UE-Magreb, como la Unión para el Mediterráneo o el proyecto Clima South.
\end{abstract}

Palabras clave: Cambio climático, Unión Europea, Magreb, COP 21 París, Clima South, Unión para el Mediterráneo.

Title in English: "Role of the European Union in the climate change negotiations"

\begin{abstract}
:
The paper analyzes the role of the European Unión in the area of climate change, as well as its main instruments of environmental cooperation in the Southern Mediterranean. Object of analysis are also the commitments the EU has taken on in the last Conferences of the Parties (COPs), its level of compliance and its ability to lead the negotiations on climate change since the Rio Summit (1992). The article points out the main commitments made by the most important actors in this international regime as well as their position in the Paris Climate Conference at the end of 2015. In the last part of the paper, the impact of cooperation initiatives EU-Maghreb, such as the Union for the Mediterranean or the Clima South project, will be analyzed.
\end{abstract}

Keywords: Climate Change, European Union, Maghreb, COP 21 Paris, Clima South, Union for the Mediterranean.

Copyright (C) UNISCI, 2015.

Las opiniones expresadas en estos artículos son propias de sus autores, y no reflejan necesariamente la opinión de UNISCI. The views expressed in these articles are those of the authors, and do not necessarily reflect the views of UNISCI.

\footnotetext{
${ }^{1}$ Xira Ruiz Campillo es profesora de Régimen Internacional del Medioambiente en la Universidad Complutense de Madrid e investigadora senior de UNISCI.

Dirección: Departamento de Estudios Internacionales, Facultad de Ciencias Políticas y Sociología, UCM, Campus de Somosaguas, 28223 Madrid, España.

Email: xiraruiz@ucm.es.

http://dx.doi.org/10.5209/rev_RUNI.2015.n39.51816
} 


\section{Introducción}

La Unión Europea es uno de los actores internacionales con mayor peso en el área del cambio climático. No es solo un actor con compromisos políticos, sino también con compromisos vinculantes y cuantificables a nivel regional, lo que le convierte en un actor creíble y líder en esta área.

Y si bien las anteriores afirmaciones son ciertas, también lo es que la UE ha tenido altibajos en su liderazgo durante las negociaciones para luchar contra el calentamiento global. Desde la Convención Marco de las Naciones Unidas sobre el Cambio Climático (CMNUCC), en 1992, hasta la última COP (Conferencia de las Partes), en Lima, en diciembre de 2014, el liderazgo de la UE en esta materia ha variado.

El año 2015 es un año clave para la acción global. Se deberán adoptar un nuevo tratado climático y un nuevo programa de desarrollo sostenible. Las discusiones y las dificultades para llegar a acuerdos están directamente relacionadas con temas tan espinosos como los hábitos de consumo en los países del Norte ${ }^{2}$ y el coste de las innovaciones para un Sur global que cada vez contamina y consume más.

El cambio está en marcha. La pregunta es si ese cambio está o no yendo al ritmo adecuado para evitar el calentamiento hasta un límite en el que la acción del ser humano ya difícilmente pueda hacer algo para revertirlo y que los expertos sitúan en el aumento de la temperatura a $2{ }^{\circ} \mathrm{C}$ de aquí a final de siglo.

En este trabajo se va a analizar la postura de la UE frente al cambio climático y sus principales instrumentos de cooperación medioambiental con sus socios al otro lado del Mediterráneo.

Dos de las principales preguntas que trato de responder en este análisis son las siguientes:

1. ¿Es la Unión Europea un actor de peso relevante en las negociaciones sobre cambio climático? Para responder a esta cuestión, voy a analizar los compromisos de la UE, económicos y políticos para luchar contra el calentamiento global. ¿Son compromisos ambiciosos? ¿Cumple la UE con sus compromisos? ¿Lidera la UE las negociaciones sobre cambio climático? ¿Cuánto destina a políticas para frenar el cambio climático?

2. ¿Qué instrumentos de cooperación tiene la Unión Europea en el Magreb para mejorar la lucha contra el cambio climático? ¿Qué programas de inversión e iniciativas públicas ha puesto en marcha? ¿Hay inversión privada que sostenga la inversión pública de la UE?

Para hacer este análisis parto de la base de que el verdadero empuje hacia una economía descarbonizada vendrá de la mano de la inversión privada. Será muy difícil realizar esa transición sin el apoyo de la industria, y aunque las instituciones públicas son las que deben promover, regular y financiar inicialmente esa transición, lo que dará una idea del cambio real será el apoyo de los principales sectores industriales en el área de la energía.

\footnotetext{
${ }^{2}$ Los hábitos de consumo en los países desarrollados es uno de los elementos clave de documentos con tanta repercusión como la Encíclica Laudato sí, del Papa Francisco I sobre ecología, mayo 2015. Además, la producción y el consumo responsables son dos de los objetivos de la Agenda 2030 para el desarrollo sostenible, adoptada por la Asamblea General de la ONU en septiembre de2015.
} 
Al igual que ocurrió en el Protocolo de Montreal, que regula la capa de ozono (1987), quien realmente puede acelerar el paso hacia un mundo con menos fósiles serán las industrias, y no necesariamente desde un punto de vista solidario con el medioambiente, sino desde un punto de vista de rentabilidad económica. Cuando el sector empresarial comience a ver en términos productivos las nuevas tecnologías, entonces no habrá marcha atrás y eso actuará como efecto dominó para el resto de las industrias.

\section{2. ¿Es la Unión Europea un actor de peso en las negociaciones sobre cambio climático?}

\section{1. ¿Lidera la UE las negociaciones sobre cambio climático?}

La Unión Europea ha liderado buena parte de las negociaciones sobre el cambio climático desde la Cumbre de Río. Incluso mucho antes ya se mostraba como un actor preocupado por el medioambiente en general; se puede decir que esa preocupación comienza a raíz de la Conferencia de Estocolmo en 1972 y se materializa a través del Acta Única Europea (1986), en la que se incluyen tres artículos que permiten a la Comunidad «la conservación, la protección y la mejora del medioambiente, la protección de la salud de las personas y la utilización prudente y racional de los recursos naturales».

Recordemos que algunos países europeos, sobre todo los más prósperos, como los nórdicos o Alemania, han sido históricamente más sensibles a las cuestiones medioambientales que los países del Sur de Europa, si bien es cierto que estos últimos han comenzado a ver, no solo las consecuencias de la no-actuación en materia medioambiental, sino también los beneficios económicos en términos de creación de empresas y generación de riqueza que supone invertir en energías renovables y en tecnología que disminuya los efectos perversos del cambio climático.

La firme postura de la UE sobre la necesidad de adoptar compromisos concretos respecto a las reducciones de gases de efecto invernadero le ha convertido en un actor con peso dentro de las negociaciones. Esto, a su vez, le ha dado también cierto prestigio en los foros internacionales medioambientales, lo que ciertamente ha ayudado a que la UE mejore su estatus en este ámbito de la escena internacional.

No obstante, este peso internacional no siempre ha sido relevante a la hora de ejercer su influencia en las negociaciones sobre un nuevo acuerdo climático. El seguimiento de la postura de la UE a lo largo de las distintas cumbres sobre el cambio climático nos hace ver que el poder de influencia de la Unión varía de forma paralela a su fortaleza económica, y eso se debe posiblemente a que en esos periodos existe una mayor fricción entre los países europeos más y menos sensibles con el medioambiente. Si bien la UE acude con una voz propia a las cumbres internacionales, también lo es que en esas cumbres hay países europeos que no apoyan claramente esa voz única e intentan retrasar las negociaciones.

Si analizamos la actuación de la UE hasta el momento, vemos que desde la Cumbre de Río (1992) hasta 2001, la UE se va a esforzar en pedir al resto de países desarrollados que adopten compromisos específicos de reducción de gases de efecto invernadero (GEI) y en adoptar dentro del ámbito europeo sus propios compromisos, siendo los europeos unos de los primeros actores en firmar el Protocolo de Kyoto. La UE se comprometió a ir más allá de la reducción del $5 \%$ de los gases regulados por Kioto, poniéndose como objetivo disminuir un $8 \%$, demostrando así su compromiso con el cambio climático.

A partir de 2001, la UE no solo continua alentando a los países desarrollados a adoptar compromisos, sino que también comienza a exigir que los países con economías en transición 
y en desarrollo empiecen a actuar y adopten también compromisos de reducción ${ }^{3}$, uniéndose así a las presiones de países como Estados Unidos, quien siempre ha advertido que no adoptaría ningún tipo de compromiso vinculante hasta que otros grandes países industrializados, como China o India, hicieran lo propio. Esta postura de la UE viene de algún modo a poner sobre la mesa de negociaciones la necesidad de que todos los estados que contaminan contribuyan a la reducción de GEI para que los esfuerzos de unos pocos no se vean ensombrecidos por la pasividad de otros. En este sentido, tanto la UE como USA entienden que un problema de bienes comunes como el cambio climático — que quizás es el mayor ejemplo de bienes comunes en el mundo actual - solo podrá solucionarse con la buena disposición de todos. Pero mientras la UE decide actuar con el ejemplo, Estados Unidos impone que los demás (especialmente los estados industrializados más contaminantes) se comprometan primero.

A partir de 2008, la UE se ve inmersa en una crisis económica mundial que acentúa las divisiones internas entre sus Estados. Esto hace que su peso internacional quede debilitado y que no pueda ejercer una influencia destacable en la gobernanza medioambiental. Un ejemplo de la rápida pérdida de peso en las negociaciones sobre cambio climático lo encontramos en la Cumbre de Copenhague en 2009. Si bien a esta cumbre la UE acudió con una propuesta innovadora y valiente contra el cambio climático, sufrió una fuerte humillación al ser relegada y aislada de las negociaciones lideradas por Estados Unidos y los países BRIC (menos Rusia) ${ }^{4}$ para redactar el Acuerdo de Copenhague ${ }^{5}$. El Acuerdo, del que solo se tomó nota porque se negoció fuera del proceso de la CMNUCC (Convención Marco de las Naciones Unidas sobre Cambio Climático), resultó novedoso y puso las bases de las negociaciones en COPs posteriores. Por ejemplo, el Acuerdo se pone como objetivo limitar el aumento de temperaturas a no más de $2{ }^{\circ} \mathrm{C}$, se establece un proceso para que todos los países (más y menos desarrollados) adopten objetivos de mitigación voluntarios, y acuerda aumentar la financiación para las actividades de mitigación y adaptación.

En Copenhague la comunidad internacional se enfrentó como nunca antes. El fuerte grupo del G77 se dividió en pequeños grupos que defendieron sus intereses particulares, Estados Unidos y China (respaldada por India) se enfrentaron por incluir o no objetivos vinculantes para todos los estados, y la Unión Europea ve como pierde liderazgo en las negociaciones. A partir de esta cumbre, coincidente con la crisis económica por la que atraviesa la eurozona, la Unión Europea muestra una serie de desavenencias internas, sobre todo entre estados más concienciados con los temas medioambientales y algunos países del Este, como Polonia, Bulgaria y Hungría, más preocupados por la posibilidad de ver cómo disminuían algunos beneficios económicos obtenidos a través de las políticas medioambientales, como las ventas de aire caliente establecidas a través del Protocolo de Kyoto.

El objetivo principal de la COP de Cancún fue el de restaurar la confianza entre estados. En Cancún se reconoce que todos los países tienen que hace esfuerzos para que las emisiones globales se reduzcan y se acepta la cifra dada por el IPCC de que el objetivo a alcanzar es la no superación del aumento de la temperatura en dos grados Celsius. En Cancún se establece el Comité de Adaptación con el fin de facilitar la adaptación de los países y promover la financiación, la transferencia de tecnología y el intercambio de información entre países. Los países desarrollados se comprometen a aportar unos 30000 millones de dólares entre 2010 y

\footnotetext{
${ }^{3}$ Chasek, Pamela, Downie, David L. y Welsh Brown, Janet (2014): Global Environmental Poltics. Sixth Edition. Colorado, Westview Press, pp. 164-165.

${ }^{4}$ Junto a Estados Unidos estaban China, India, Brasil y Sudáfrica.

${ }^{5}$ Verdú Baeza, Jesús: "Cambio Climático y la Unión Europea: desde el liderazgo al riesgo de la irrelevancia", Revista de Derecho Comunitario Europeo, no 45, mayo/agosto 2013.
} 
2012 a canalizar mayoritariamente a través del creado Fondo Verde para el Clima y a movilizar 100000 millones de dólares anuales a partir del año 2020.

Desde la cumbre de Copenhague, la Unión Europea - a pesar de las reticencias de algunos de sus estados miembros - ha actuado como el alumno aventajado que quiere seguir avanzando en las negociaciones y pide de forma insistente que todos los demás actúen rápidamente y sigan sus pasos.

Así, en la COP de Durban, en 2011, la UE promueve con éxito el inicio de un periodo de negociaciones que condujeran a un nuevo acuerdo a través de la conocida como Plataforma de Durban para la Acción Reforzada. La Plataforma de Durban tendría como misión negociar un nuevo acuerdo para ser firmado en 2015 y que entrara en vigor en 2020. En Durban también se aprueban las modalidades y procedimientos para la transferencia de tecnología, uno de los grandes temas a negociar en París y que sin duda ocupará buena parte de las discusiones para conseguir que los países en desarrollo hagan más fácil el acceso a la tecnología a los países más vulnerables.

Para evitar un vacío entre Kioto y el nuevo acuerdo, en Doha 2012 se acuerda establecer un nuevo periodo para el Protocolo de Kioto, que fue el mayor éxito de esta cumbre en la que los críticos destacaron la falta de ambición y de urgencia de los estados participantes ${ }^{6}$. Aunque los resultados en Doha no fueron demasiado destacables, lo cierto es que la Unión Europea salió con la sensación de que había cumplido todos sus objetivos: 1. Conseguir que todos los países (independientemente de su grado de desarrollo) tuvieran que hacer compromisos de reducción de emisiones, terminando así con el viejo sistema de compromisos solo para los países desarrollados ${ }^{7}$. 2. Establecer la Plataforma de Durban como el único foro de negociación del nuevo acuerdo sobre cambio climático. 3. Prohibición de vender aire caliente adicional durante el periodo de extensión de Kioto. 4. Acordar un plan de trabajo hasta 2015 e identificar más medidas para reducir emisiones ${ }^{8}$.

En la COP de Varsovia en 2013 no se logró alcanzar ningún avance significativo en relación al nuevo acuerdo sobre cambio climático, aunque la UE consiguió transmitir el sentido de urgencia con el que todos debían actuar para que en 2015 hubiera objetivos y compromisos claros con los que cerrar un nuevo acuerdo9. Paradójicamente, Polonia, el país anfitrión fue acusada por la propia Comisión Europea de retrasar de forma deliberada las negociaciones y se terminó la cumbre con la sensación de que la Unión Europea no había podido dominar a Polonia, quien favoreció los intereses de la industria de los combustibles fósiles y del carbón nacional ${ }^{10}$. El resultado más destacable y al que se llegó después de duras negociaciones fue la aprobación del llamado Mecanismo de Varsovia, creado para apoyar a los países en desarrollo a enfrentar los daños y pérdidas causados por el cambio climático, como las sequías, las olas de calor o el aumento del nivel del mar. Este mecanismo fue, sin duda, un éxito para los países del Sur, que reclamaban desde hacía años más ayuda por parte

\footnotetext{
${ }^{6}$ Greenpeace: Talks fail to meet pace of climate change, 8 diciembre 2012, en http://www.greenpeace.org/international/en/press/releases/Talks-fail-to-meet-pace-of-climate-change--Greenpeace--/

${ }^{7}$ European Commission: Doha climate change conference (COP 18/CMP 8). 26 noviembre - 8 diciembre 2012, en http://ec.europa.eu/clima/events/articles/0062 en.htm

${ }^{8}$ Hedegaard, Connie: "Why de Doha climate conference was a success", The Guardian, 14 diciembre 2012, en http://www.theguardian.com/environment/2012/dec/14/doha-climate-conference-success

${ }^{9}$ Warsaw Climate Change Conference (COP 19 / CMP 9). 11-23 noviembre 2013, en http://ec.europa.eu/clima/events/articles/0086 en.htm

10 "As the Warsaw climate talks end, the hard work is just beginning", The Guardian, 25 noviembre 2013, en http:/www.theguardian.com/environment/2013/nov/25/warsaw-climate-talks-end-cop19-2015, Inspira Action: La cumbre de cambio climático de Varsovia fracasa, noviembre 2013, en https://www.inspiraction.org/noticias$\underline{\text { inspiraction/archivo/201311 }}$
} 
de los países desarrollados. Está por ver si este nuevo mecanismo consigue materializarse en ayudas y en gestos concretos.

Tras el fracaso de celebrar una cumbre sobre cambio climático en un país hostil como Polonia, la Unión Europea recupera su protagonismo en Lima, adonde llegó con el propósito de conseguir que se establecieran unos objetivos transparentes, cuantificables y comparables para la reducción de las emisiones, y donde finalmente todos los países sin excepción acordaron un texto en el que se comprometieron a presentar ante la ONU sus contribuciones previstas y determinadas a nivel nacional (INDC por sus siglas en inglés) a lo largo de 2015. Además, la UE presentó un borrador o non-paper para el acuerdo de París que, si bien fue criticado por varios países en vías de desarrollo por ser poco sensible con la realidad de los países del Sur, no deja de ser una muestra más de liderazgo y del compromiso europeo con el cambio climático ${ }^{11}$. Este nuevo periodo de liderazgo, fomentado por la necesidad que la Unión Europea tiene de que de París salga un acuerdo que le encumbre como líder en las negociaciones sobre cambio climático, también coincide con la mejora económica que está experimentando la eurozona.

Después de Lima, y siguiendo con su retomado papel de liderazgo, la Comisión Europea publica el Energy Union Package, donde detalla todos los pasos que ha dado hasta ese momento para reducir sus emisiones, los pasos que deberían seguir todas las partes para que en París se llegue con los compromisos cumplidos, qué debería incluir el nuevo acuerdo para ser efectivo y su objetivo de establecer el cambio climático como una prioridad estratégica en los diálogos políticos, incluyendo sus citas en el G7 y el G20 ${ }^{12}$. A esto hay que añadir la gran presión diplomática que la UE ha puesto en marcha en 2015 para conseguir que en París se firme un nuevo acuerdo. Este impulso diplomático incluye por ejemplo a 90000 diplomáticos y más de tres mil misiones para presionar al resto de países en la necesidad de alcanzar un acuerdo exitoso a finales de este año ${ }^{13}$.

\subsection{La Unión Europea y los principales actores ante la COP de PARÍS 2015}

Los estados ya han comenzando a transmitir a Naciones Unidas sus contribuciones nacionales para la lucha contra el cambio climático. A continuación exponemos brevemente las posturas y compromisos adoptados por los principales actores internacionales ante la firma del nuevo acuerdo climático. Esto nos permitirá analizar el nivel de los compromisos de la UE y la fortaleza del futuro nuevo acuerdo que debería firmarse en París.

La Unión Europea es la única potencia hasta ahora en adoptar una decisión vinculante para reducir un $40 \%$ de emisiones en 2030 (respecto a niveles de 1990) y un abastecimiento de al menos un $27 \%$ mediante fuentes renovables. Además, se ha comprometido a reducir sus emisiones en $80-95 \%$ para el año 2050 si se da el contexto de reducciones necesarias que, de acuerdo al IPCC, deben hacer los países desarrollados en conjunto. Esto, que se ha anunciado como un objetivo ambicioso para un actor tan diverso como la UE, ha sido criticado por diversas organizaciones ecologistas como falto de ambición y como un objetivo al que la UE llegará sin apenas esfuerzos. Un objetivo arriesgado y que realmente marcara la diferencia hubiera sido — según estos grupos - una reducción del $55 \%$ de los gases de efecto invernadero en 2030 y un objetivo del $45 \%$ de fuentes renovables, lo que de algún modo

\footnotetext{
11 "EU raises the pressure on COP 20 conference", Euroactiv, 8 diciembre 2014, en http://www.euractiv.com/sections/climate-environment/eu-raises-pressure-cop-20-conference-310633

12 Comisión Europea: Energy Union Package. The Paris Protocol - A blueprint for tacking global climate change beyond 2020. Communication from the Commission to the European Parliament and the Council. Brussels, 25.2.2015. COM(2015) 81 final.

13 "EU to launch diplomatic offensive ahead of Paris climate talks", Euroactiv, 20 enero 2015, en http://www.euractiv.com/sections/climate-environment/eu-launch-diplomatic-offensive-ahead-paris-climatetalks-311418
} 
forzaría la transformación del sistema energético ${ }^{14}$. A pesar de las críticas, los objetivos europeos siguen siendo ambiciosos si los comparamos con los objetivos del resto de países desarrollados.

La Unión Europea defenderá en París que se incluya un mecanismo de revisión de los compromisos nacionales cada cinco años; que se incluyan mecanismos de flexibilidad para alcanzar los compromisos de mitigación, y defenderá las acciones de adaptación como un elemento central en el acuerdo final ${ }^{15}$.

Aunque la Unión Europea se haya marcado unos objetivos que para otros son inalcanzables, los dos países que realmente marcarán el camino en París son China y Estados Unidos. Ambas potencias han protagonizado históricamente posturas enfrentadas sobre cómo y cuándo actuar contra el cambio climático. La novedad que hace que a París se llegue con algo de optimismo es que ambos han asumido una serie de compromisos que suponen un cambio en sus posiciones tradicionales durante las negociaciones.

China ha invertido fuertemente en los últimos años para transformar su sector industrial e introducir poco a poco las tecnologías renovables.

En Cancún se comprometió a reducir sus emisiones de dióxido de carbono por unidad de PIB en un 40-45\% en 2020 sobre la base de 2005 y aumentar el consumo de energía no fósil en un $15 \%$ para 2020 .

Lo anterior viene respaldado por las políticas puestas en marcha por los sucesivos planes quinquenales, y en especial el número doce (2011-2015), en el que propone un cambio estructural de la industria del país, donde la inversión en los combustibles no-fósiles, las fuentes renovables, las nuevas materias primas y los medios de transporte alternativos sean la punta de lanza para conseguir modernizar la industria china a la vez que reduce su consumo de carbón, algo que ya está empezando a conseguir ${ }^{16}$.

El primer ministro chino, Li Keqiang, parece dispuesto a emprender una batalla contra la contaminación y a que su economía crezca, pero no a expensas del medioambiente ${ }^{17}$, por lo que ha puesto en marcha reformas para cambiar tanto la forma en que se produce la energía como en su forma de consumo. China está invirtiendo grandes cantidades en combatir la contaminación de los campos agrícolas, en mejorar la contaminación de las aguas y en combatir la desertificación. Además, está cambiando la legislación para multar a los contaminadores y compensar a las víctimas de daños medioambientales ${ }^{18}$. A estos esfuerzos

\footnotetext{
${ }^{14}$ Greenpeace: La Unión Europea debe intensificar la acción climática y energética de cara a 2030, noviembre 2013, en http://www.greenpeace.org/espana/Global/espana/report/cambio_climatico/gp_objetivosUE_clima_2030\%20\%2 8 Noviembre $\% 29$. pdf

${ }^{15}$ Consejo de la Unión Europea: Preparations for the 21th session of the Conference of the Parties (COP 21) to the United Nations Framework Convention on Climate Change (UNFCCC) and the $11^{\text {th }}$ session of the Meeting of the Parties to the Kyoto Protocol (CMP 11), Paris 2015, 18 septiembre 2015.

${ }^{16}$ China consiguió por primera vez en 2014 reducir el consumo de carbón. "China set to list greenhouse gas reduction goals, at cost topping \$6 trillion", Japan News, 24 junio 2015, en

http://www.japantimes.co.jp/news/2015/06/24/asia-pacific/china-set-list-greenhouse-gas-reduction-goals-costtopping-6-trillion/

${ }^{17}$ The Climate Group: New Premier Li Keqiang pledges to use 'iron fist' on China's pollution, 18 marzo 2013. En http://www.theclimategroup.org/what-we-do/news-and-blogs/new-premier-li-keqiang-pledges-to-use-ironfist-on-chinas-pollution/

${ }^{18}$ Reuters: China to 'declare war' on pollution, premier says, 4 marzo 2014, en http://www.reuters.com/article/2014/03/05/us-china-parliament-pollution-idUSBREA2405W20140305
} 
hay que añadirles el reciente anuncio de creación de un mercado de emisiones para el año 2017 que sobrepasará al de la Unión Europea (el mayor hasta el momento) ${ }^{19}$.

En noviembre del pasado año, el país se comprometió a que el pico de sus emisiones se produzca en 2030 como muy tarde y a que a partir de esa fecha aumente el uso de energía nofósil en al menos un 20\%. De hecho, en 2014, China fue el mayor inversor mundial en energía renovable, habiendo invertido un 39\% más que en el año anterior y un $55 \%$ más que el segundo inversor mundial en energía renovable, Estados Unidos ${ }^{20}$.

Los esfuerzos que está haciendo China para convertirse en un país más respetuoso con el medioambiente son enormes y, analizando los resultados que está obteniendo hasta el momento, es factible que el país consiga alcanzar buena parte de los compromisos propuestos.

China (también India) insiste en todas las cumbres en la necesidad de que se respete el principio de responsabilidades comunes, pero diferenciadas y se niega a que este principio caiga en el olvido. Es decir, China defiende que siga habiendo una deferencia especial hacia los países en vías de desarrollo y que los países desarrollados asuman su responsabilidad en el estado actual del cambio climático. Así, China insiste en que los países desarrollados tienen la obligación de apoyar económicamente la transición en los países en vías de desarrollo. China pidió en Lima (dentro del bloque BASIC: Brasil, Sudáfrica, India y China) avances en la financiación a largo plazo, una hoja de ruta para movilizar los 100000 millones de dólares para el 2020 y un Mecanismo de Varsovia completamente funcional. Para China, los países desarrollados tienen que tener unos objetivos claros de reducción y los PVD deben tener flexibilidad para diseñar sus contribuciones. En París, China seguirá pidiendo una diferenciación entre países desarrollados y en vías de desarrollo y un mayor compromiso financiero por parte de los países desarrollados. Tanto su predisposición como la de India serán clave para llegar a un acuerdo.

Estados Unidos será uno de los grandes protagonistas en París y uno de los grandes impulsores de un nuevo acuerdo a tenor de los últimos esfuerzos que está haciendo la administración Obama. El país es el segundo mayor emisor de gases de efecto invernadero a nivel mundial, por lo que su implicación y compromiso son clave para que cualquier acuerdo que se alcance sea efectivo. Hasta la fecha, países como China, India y Brasil han jugado con los compromisos evasivos de Estados Unidos y se habían negado a adoptar compromisos vinculantes si Estados Unidos no lo hacía también.

En noviembre de 2014, semanas antes de la Cumbre de Lima, Estados Unidos anunció durante una reunión con China un objetivo de reducción de emisiones de un 26\%-28\% con respecto a 2005 para el año 2025 y un esfuerzo por llegar al $28 \%$ en esa misma fecha. Todo ello supone un objetivo más ambicioso que el propuesto en la cumbre de 2010 en Cancún.

El Plan de Acción contra el Cambio Climático presentado por Obama en 2013 incluye medidas globales para tratar este problema desde diversos ámbitos: desde la financiación de proyectos energéticos y la promoción de energías renovables hasta el apoyo a las comunidades locales en la identificación de los impactos del cambio climático ${ }^{21}$.

En agosto, Obama ha vuelto a demostrar su compromiso con el cambio climático y con la conferencia de París, presentando el Plan de Energía Limpia para reducir las emisiones de carbono de las centrales eléctricas en Estados Unidos. Con este nuevo plan, se pretende

\footnotetext{
19 "China to launch national cap-and-trade plan in 2017, US announces", The Guardian, 25 septiembre 2015.

${ }^{20}$ UNEP: Global Trends in Renewable Energy Investment 2015, en http://fs-unep-centre.org/publications/globaltrends-renewable-energy-investment-2015

${ }^{21}$ Executive Office of the President: The President's Climate Action Plan, (junio 2013), en https://www.whitehouse.gov/sites/default/files/image/president27sclimateactionplan.pdf
} 
reducir para el año 2030 en un 32\% las emisiones de las centrales termoeléctricas respecto a niveles de 2005.

Otro de los grandes protagonistas en París será la India, uno de los mayores emisores a nivel global, pero uno de los que menos emite per cápita. La India ya se comprometió en Cancún a reducir la intensidad de sus emisiones en un $20-25 \%$ en 2020 con respecto a $2030^{22}$, y hasta la fecha ha aumentado sustancialmente los impuestos sobre el carbón para favorecer la inversión en energías limpias ${ }^{23}$ y ha puesto en marcha un ambicioso y costoso plan de reforestación ${ }^{24}$. Estas dos áreas (energías limpias y reforestación) son el eje central de la contribución de India a la cumbre de París. En su contribución, India propone (sin asumir ninguna obligación y sin esclarecer una fecha para su pico de emisiones) reducir la intensidad de sus emisiones entre un 33\% y un 35\% en el año 2030 (con respecto a niveles de 2005) y conseguir que el $40 \%$ de la energía provenga de fuentes renovables ese mismo año. India advierte, no obstante, que todo ello dependerá de la transferencia de tecnología por parte de los países desarrollados y del acceso al Fondo Verde para el Clima ${ }^{25}$.

India será uno de los países que liderarán las conversaciones en París y cuyo compromiso es necesario para que cualquier acuerdo que se adopte sea efectivo y suponga un cambio en el estado actual del calentamiento global. La postura oficial de la India en las negociaciones sobre el cambio climático se centran en la defensa del histórico principio de responsabilidades comunes pero diferenciadas y en la necesidad de que los países desarrollados asuman sus responsabilidad en el estado de la contaminación actual antes de esperar acciones por parte de los países en desarrollo. Para India, cualquier nuevo instrumento debe incluir elementos como la mitigación, la adaptación, financiación, desarrollo tecnológico y transferencia, transparencia y acción, y apoyo y desarrollo de capacidades.

Al igual que China, India se opone a cualquier modificación y reinterpretación de la CMNUCC, sus principios o anexos. Defiende un mecanismo de castigo para los países desarrollados y pide concesiones tecnológicas para que los PVD puedan actuar ${ }^{26}$. India también centrará su discurso en la necesidad de que los países desarrollados asuman un estilo de vida menos ostentoso y más respetuoso con el cambio climático, haciendo así énfasis en la necesidad de adaptación y no tanto en la de mitigación de emisiones, que es la preferencia de los países desarrollados.

Brasil, el séptimo estado emisor, se comprometió en Cancún a reducir entre un $36.1 \%$ y un $38.9 \%$ sus emisiones previstas para 2020, lo que equivale a estabilizar sus emisiones con respecto a las de 2005. Brasil acude a París con la mejora del compromiso adquirido en Cancún: reducir en un 37\% las emisiones en 2025 y en un $43 \%$ en 2030 (con respecto a niveles de 2005). Para alcanzar sus objetivos, Brasil se propone reforzar sus esfuerzos en las áreas de la energía (aumentando el consumo de biocombustibles y de energía renovable) y en el área forestal (con mejores leyes para controlar las talas ilegales y a través de políticas de reforestación). Estos compromisos, avisa Brasil, se harán efectivos siempre y cuando de París

\footnotetext{
22 En estas emisiones no se tienen en cuenta las emisiones relacionadas con la agricultura, y que son consideradas como emisiones de supervivencia.

${ }^{23}$ Smiti Mittal: "India doubles tax on coal to fund clean energy, environmental projects", Clean Technica, 20 julio 2014. En http://cleantechnica.com/2014/07/20/india-doubles-tax-coal-fund-clean-energy-environmentalprojects/

24 "Green road to Paris", The Indian Express, 13 mayo 2015, en http://indianexpress.com/article/opinion/columns/green-road-to-paris/

${ }^{25}$ Gobierno de la India: India's Intended Nationally Determined Contribution: working towards climate justice, (1 octubre 2015), en http://www4.unfccc.int/submissions/INDC/Published\%20Documents/India/1/INDIA\%20INDC\%20TO\%20UNFCCC.pdf ${ }^{26}$ Declaración conjunta China-India, 15 mayo 2015, en http://pmindia.gov.in/en/news updates/joint-statementon-climate-change-between-india-and-china-during-prime-ministers-visit-to-china/
} 
salga un acuerdo jurídicamente vinculante y que respete el principio de responsabilidades comunes pero diferenciadas ${ }^{27}$.

Del grupo de países BASIC, Brasil es el que más fuertemente apuesta por la reducción de emisiones. A nivel interno, tiene varias leyes forestales centradas en la conservación de bosques, si bien desde que el mayor propulsor de la lucha contra la deforestación y el cambio climático, Lula da Silva, ya no está en el gobierno, Brasil ha empeorado sus resultados y en 2013 aumentó la deforestación por primera vez desde $2004^{28}$ y la presidenta actual ha sido acusada de titubear en el freno a la deforestación, que, recordemos, es una parte fundamental para la economía y el desarrollo del país.

Las propuestas de Brasil van en la dirección de definir las contribuciones de mitigación de todas las partes, pero que esas contribuciones sean primero definidas a nivel nacional y teniendo en consideración la responsabilidad histórica al cambio climático.

Para Brasil, la financiación y la ayuda tecnológica de los países desarrollados son clave para que los PVD se adapten y mitiguen el cambio climático, y defiende que los objetivos de mitigación sean de naturaleza voluntaria para los PVD.

Rusia, el cuarto estado emisor, ha comunicado un objetivo de reducción del $25-30 \%$ para 2030 con respecto a niveles de $1990^{29}$, considerado inadecuado, pero dependiendo de algunas condiciones, como que todos los principales emisores firmen un acuerdo vinculante para reducir sus emisiones. Rusia está a favor de la diferenciación entre países en función de la información científica, el desarrollo socioeconómico, las características geográficas, climatológicas y naturales de cada país.

La postura que Rusia adoptará en París no está clara. Rusia ha participado en muchas negociaciones como parte del grupo UMBRELLA junto con Australia, Canadá y Estados Unidos; en otras se ha aliado con los BRIC. Los compromisos que ha anunciado Rusia son confusos y en las últimas reuniones Rusia ha demostrado cierta indiferencia con respecto al cambio climático ${ }^{30}$.

Sudáfrica, el doceavo estado emisor, ha comunicado su compromiso de reducción que se ha considerado también inadecuado al ser inconsistente con el propósito de no superar los 2 grados centígrados ${ }^{31}$. Su objetivo es alcanzar un pico de emisiones entre 2020 y 2025 manteniendo este nivel estable en la siguiente década. Los niveles de polución quedarian fijados entre 398 megatoneladas y 614 megatoneladas de CO2 entre 2025 y 2030, llegándose a una reducción en 2050 de entre 212 y 428 megatoneladas. Para ello Sudáfrica piensa potenciar las energías renovables.

AOSIS, los pequeños estados insulares, es sin duda el grupo de países más interesado en conseguir un acuerdo vinculante fuerte contra el cambio climático e históricamente ha sido muy activo en las negociaciones del régimen internacional a pesar de que en el grupo están

\footnotetext{
${ }^{27}$ República Federativa de Brasil: Federative Republic of Brazil Intended Nationally Determined Contribution towards achieving the objective of the United Nations Framework Convention on Climate Change, 28 septiembre 2015.

28 "La deforestación en Brasil aumenta por primera vez en una década", El País, 13 noviembre 2014,en http://imazon.org.br/categorias/the-state-of-amazon/?lang=en

${ }^{29}$ Año en que la Unión Soviética emitía grandes cantidades de gases de efecto invernadero, cantidades que se redujeron posteriormente.

${ }^{30}$ Responding to Climate Change: Ahead of Paris, Russia becomes a climate policy wallflower, 29 julio 2015, en http://www.rtcc.org/2015/07/29/ahead-of-paris-russia-becomes-a-climate-policy-wallflower/

${ }^{31}$ Véase "South Africa", Climate Action Tracker, donde se afirma que "si la mayoría de los demás estados siguiesen la aproximación que realiza Sudáfrica, el calentamiento global podría exceder de los $3-4^{\circ} \mathrm{C}$ ", en http://climateactiontracker.org/countries/southafrica.html
} 
algunos de los países menos desarrollados del mundo. Los países AOSIS presentaron en su día el primer borrador del Protocolo de Kyoto, algo insólito en otros regímenes internacionales. Los países AOSIS van más allá en su petición y quieren que la comunidad internacional se comprometa a reducir en un $1.5^{\circ} \mathrm{C}$ el aumento de la temperatura global, aduciendo que esta es la única manera de detener el aumento del nivel del mar.

Algo muy positivo y que demuestra de algún modo el giro que se está produciendo por parte de los países en desarrollo es el caso de los países AILAC ${ }^{32}$ y México. Ambos forman parte del grupo de países en desarrollo que quieren demostrar que pueden ser protagonistas del cambio hacia una economía baja en carbono. México, primer país del Sur global en presentar ante Naciones Unidas sus contribuciones y cuyas emisiones globales se estiman en alrededor del $1.5 \%$, se ha marcado el objetivo de comenzar a reducir sus emisiones en 2026, a la vez que alentaba al resto de países emergentes a presentar sus contribuciones ${ }^{33}$.

Los países AILAC, de los que tan poco se ha hablado, formalizaron su alianza en la Cumbre de Doha (2012) con la intención de comenzar a hacer esfuerzos sin esperar a recibir la ayuda económica de los países desarrollados, demostrando así su compromiso con el cambio climático. Este grupo de países quiere superar la discusión clásica entre países desarrollados y países en desarrollo o países del Norte y del Sur global, demostrando que hay países que no están ni en uno ni en otro grupo en las discusiones, que quieren superar esa tradicional separación entre unos y otros y que pueden y quieren comprometerse de forma vinculante para detener el calentamiento global ${ }^{34}$. Ante la pérdida de poder de grupos históricos como el G77, es muy posible que sean bloques como AILAC los que consigan presionar al resto de países en desarrollo para que se unan en un nuevo tratado en París. Este grupo se revela así como una alternativa a tener en cuenta a la hora de conseguir que el resto de países se sumen y se supere la dicotomía y las sempiternas discusiones Norte-Sur.

A pesar del optimismo que anuncios como los de la Unión Europea, China o Estados Unidos aportan, las negociaciones en París serán difíciles, pues hay en juego demasiados intereses políticos, económicos, empresariales e incluso intereses por posicionarse como actores clave durante las negociaciones. La Unión Europea celebrará en octubre una conferencia para hacer balance de las contribuciones que han hecho cada uno de los países y para valorar el nivel de ambición general. La UE está haciendo grandes esfuerzos para impulsar el proceso y que se llegue a París en un clima positivo en el que todos estén convencidos de que se tiene que aprobar un texto que sustituya a Kioto. La Unión es un actor bien posicionado y creíble a la hora de ejercer de maestro de ceremonias. Ante los ojos de la comunidad internacional, la UE ha cumplido con sus compromisos hasta el momento y ningún otro estado podrá criticar que no esté haciendo lo suficiente para conseguir un nuevo tratado. Pero las discusiones serán duras y largas, centradas en temas espinosos como la financiación de la mitigación y la adaptación, el carácter vinculante o no del nuevo tratado o la distinción entre países desarrollados y en desarrollo. Aunque todos quieran un nuevo tratado, las discusiones clave estarán en esas otras áreas.

\footnotetext{
${ }^{32}$ Alianza Independiente de estados de Latinoamérica y Caribe. Está compuesta por Colombia, Perú, Costa Rica, Chile, Guatemala, Panamá y el apoyo de la República Dominicana. Se formó oficialmente en Doha 2012, donde habló con voz propia. Está formado por países medios que han puesto en marcha medidas de mitigación y reducción ambiciosas, muchas de ellas al nivel de los países desarrollados o incluso superiores. Pretenden ser vistos como un ejemplo para el resto de países en desarrollo.

33 "México marca un hito con su promesa de reducir la contaminación de gases de efecto invernadero", Scientific American, 3 abril 2015, en http://www.scientificamerican.com/espanol/noticias/mexico-marca-un-hito-con-supromesa-de-reducir-la-contaminacion-de-gases-de-efecto-invernadero/

${ }^{34}$ Brookings: A New Latin American Climate Negotiating Group: The Greenest Shoots in the Doha Desert, 12 diciembre 2012, en http://www.brookings.edu/blogs/up-front/posts/2012/12/12-latin-america-climate-roberts
} 
Pase lo que pase en París, la solución real al cambio climático no está tanto en los grandes acuerdos -absolutamente necesarios para que la comunidad internacional vaya en una misma dirección-, sino en las acciones que se pongan en marcha a nivel bilateral o regional, como el compromiso común que adoptaron Estados Unidos y China de reducir sus emisiones $^{35}$, los proyectos Unión Europea-Magreb para mejorar la eficiencia energética, los acuerdos entre Brasil y Alemania para combatir la deforestación y la pérdida de biodiversidad $^{36}$, o el acuerdo entre China e India para desarrollar tecnologías limpias ${ }^{37}$.

Son esos pequeños proyectos los que harán que se produzcan cambios reales en el medioambiente, porque el régimen internacional del medioambiente ha demostrado que cuando es difícil ponerse de acuerdo ante la gran cantidad de actores involucrados, las decisiones que se toman por consenso son acuerdos de mínimos, pero luego existe espacio para que aquellos actores que quieren avanzar más lo puedan hacer, bien a nivel regional (caso de la Unión Europea), bien a nivel estatal o bien a nivel local (caso del Pacto de los Alcaldes ${ }^{38}$ para mejorar la eficiencia energética en sus municipios).

\subsection{Los compromisos y la estrategia de la Unión Europea}

La Unión Europea tiene dos estrategias para combatir el cambio climático que se complementan y que son igual de necesarias para que los esfuerzos tengan un impacto real. Por un lado, tiene una política de mitigación de los efectos del cambio climático, y por otro, una estrategia para adaptarse al cambio. Tanto la mitigación como la adaptación son consideradas los dos pilares para hacer frente al calentamiento global.

La UE es muy consciente de las consecuencias que el cambio climático ya está teniendo en su territorio: desde la pérdida de diversidad biológica en el Ártico hasta la disminución de las lluvias o el aumento de incendios en la zona del Mediterráneo ${ }^{39}$.

El Objetivo 20-20-20 de la UE, adoptado en 2009, tiene tres objetivos:

$\checkmark$ Reducir un 20\% las emisiones de gases de efecto invernadero a niveles de 1990 .

$\checkmark$ Aumentar en un 20\% el consumo de energía proveniente de fuentes renovables.

$\checkmark$ Mejorar en un 20\% la eficiencia energética.

De acuerdo a las proyecciones realizadas, se estima que en 2020 se conseguirá un $21 \%$ de emisiones menos que en 1990, por lo que la UE alcanzaría cómodamente el objetivo que se ha autoimpuesto, si bien hay trece países que necesitarán esfuerzos extras; entre ellos se encuentran países como Alemania, Polonia, Luxemburgo y España ${ }^{40}$.

\footnotetext{
35 "EE.UU. y China se comprometen a reducir sus emisiones contaminantes", $A B C, 12$ noviembre 2014, en http:/www.abc.es/internacional/20141112/abci-acuerdo-clima-china-eeuu-201411120624.html

36 EU-BRASIL: Brazil-Germany: Commitment in the fight against deforestation and many cooperation agreements, 25 agosto 2015, en http:/www.eubrasil.eu/en/2015/08/25/brazil-germany-commitment-in-the-fightagainst-deforestation-and-many-cooperation-agreements/

${ }^{37}$ Ministerio de Asuntos Exteriores de India: Joint Communiqué of the Republic of India and the People's Republic of China, 16 diciembre 2010,en

http://mea.gov.in/bilateral-

documents.htm?dtl/5158/Joint + Communiqu + of + the + Republic + of + India + and + the + Peoples + Republic + of + China

${ }^{38}$ Pacto de los Alcaldes, en http://www.pactodelosalcaldes.eu/

${ }^{39}$ EEA: Key observed and projected climate change and impacts for the main regions in Europe, enero 2015. http://www.eea.europa.eu/data-and-maps/figures/key-past-and-projected-impacts-and-effects-on-sectors-for-themain-biogeographic-regions-of-europe-3. También en: European Commission: The EU Strategy on adaptation to climate change (2013), p. 3, en http://ec.europa.eu/clima/publications/docs/eu strategy en.pdf

${ }^{40}$ Comisión Europea: Progress towards achieving the Kyoto and EU 2020 objective, octubre 2014, p. 9.
} 
A través de su estrategia de adaptación, la UE tiene como objetivo aumentar la resistencia de la población al cambio climático haciendo, por ejemplo, que los estados adopten estrategias nacionales de adaptación, especialmente en sectores vulnerables como la agricultura o la pesca.

¿Ha cumplido la UE sus compromisos? Esta pregunta la respondemos analizando primero las acuerdos firmados en, principalmente, la COP de Cancún, que podría considerarse como la conferencia donde se superan las diferencias entre estados aparecidas en Copenhague y donde comienza el impulso hacia un nuevo acuerdo vinculante para todos los estados.

2.3.1. En los Acuerdos de Cancún (2010) se formalizó el compromiso de los países desarrollados de dar casi \$30 000 millones en los años 2010-2012 para ayudar a los países en desarrollo a dar pasos de forma inmediata para reducir sus emisiones y poner en marcha otro tipo de iniciativas. La Unión Europea dio €7 340 millones para ese periodo cuando lo comprometido había sido contribuir con €7 200 millones (aproximadamente, un 26\% del total $)^{41}$.

2.3.2. A largo plazo, los Acuerdos de Cancún también establecían el compromiso de los países del Norte para dotar al nuevo mecanismo establecido, el Fondo Verde para el Clima, con $\$ 100000$ millones para el año 2020. Una vez dotado de esa cantidad, el Fondo Verde será el encargado de repartir los fondos entre recursos para la mitigación y recursos para la adaptación. Este punto será uno de los más debatidos en París, ya que los países en desarrollado han pedido reiteradamente desde la COP de Cancún que los países desarrollados aportaran su parte al Fondo Verde. Como ejemplo, si bien en la última COP se consiguieron recaudar \$10 200 millones, parte de los cuales provenían de países en desarrollo como Perú y Colombia, a fecha de junio de 2015 solo $\$ 4000$ millones se habían desbloqueado realmente ${ }^{42}$. Parece, no obstante, que estamos en un buen momento de promesas y tanto países como organismos, como el Banco Mundial o el Banco Interamericano de Desarrollo, se están apresurando a comprometer financiación para el cambio climático, por lo que hay buenas perspectivas de que finalmente la comunidad internacional logre llegar a los 100000 millones puestos como meta ${ }^{43}$ :

La intención de la UE es movilizar fuentes públicas, privadas, bilaterales y multilaterales para cumplir con su compromiso, ya que considera clave la movilización de fuentes de financiación privada para conseguir una economía baja en emisiones. Este será sin duda un punto de fricción durante las negociaciones en París, puesto que muchos países en desarrollo apuntan con acierto que primar la inversión privada conducirá a que solo haya proyectos en zonas de interés estratégico para las empresas, dejando así de lado otros proyectos que, si bien menos rentables económicamente, son igualmente necesarios para paliar y afrontar los efectos del cambio climático.

La Unión ha demostrado históricamente su compromiso con la ayuda a los países en desarrollo para preservar el medioambiente y luchar contra el cambio climático en particular, sin embargo, para que esos apoyos financieros tengan un efecto real y que marquen una

\footnotetext{
${ }^{41}$ Comisión Europea: Fast-start Finance, en http://ec.europa.eu/clima/policies/finance/faststart/index_en.htm

${ }^{42}$ Tout comprendre aux négociations climatiques, Le Monde, 3 junio 2015, en http://www.lemonde.fr/climat/article/2015/06/03/tout-comprendre-aux-negociationsclimatiques_4646225_1652612.html\#

${ }^{43}$ World Bank: Funding boost for climate action, 10 octubre 2015, en http://www.worldbank.org/en/news/feature/2015/10/10/funding-boost-for-climate-action.
}

Y Banco Interamericano de Desarrollo: BID anuncia intención de duplicar su financiamiento para cambio climático, 8 octubre 2015 , en

http://www.iadb.org/es/noticias/comunicados-de-prensa/2015-10-08/duplicar-su-financiamiento-para-cambioclimatico, $11272 . h$ tml 
diferencia, el resto países desarrollados también deberían apoyar firmemente a los países en desarrollo en su lucha contra el cambio climático. Durante el periodo 2007-2013, por ejemplo, un $8 \%$ del presupuesto europeo estuvo destinado a proyectos y programas relacionados con el clima en países en desarrollo ${ }^{44}$. Esa ayuda se ha dado tanto a través de acuerdos bilaterales como a través de programas multilaterales gestionados por organismos como Naciones Unidas.

Desde 2007, la UE ha realizado unas contribuciones de casi $€ 1000$ millones, combinados con unos $€ 6000$ millones en formas de préstamos de instituciones financieras europeas y bancos de desarrollo regional que han servido para financiar más de 120 proyectos climáticos.

Entre los instrumentos que tiene para mejorar la cooperación con terceros estados está el Fondo Fiduciario UE-África para Infraestructuras, o la Facilidad de Inversiones para América Latina (LAIF), el Caribe (CIF) o los acuerdos UE-ACP (Asia, Caribe, Pacífico), entre otros; teniendo todos ellos en común ayudar al desarrollo de infraestructuras clave y de tecnologías punta, y la mejora de las condiciones y la productividad económica. Desde el año 2010, en todos esos instrumentos se incluyen consideraciones para fortalecer la resistencia al clima, lo que se conoce como «ventanas climáticas».

Además del presupuesto europeo, también hay que tener en cuenta los fondos movilizados a través del Banco Europeo de Inversiones (BEI), actor clave a la hora de apoyar nuevas tecnologías limpias y resistentes al clima y a la hora de cofinanciar la mitigación y la adaptación. Parte del plan operacional del BEI para los años 2014-2016 es que al menos el $25 \%$ de la actividad total esté relacionada con la acción climática. A través de proyectos de financiación, solo en 2013 destinó $€ 19000$ millones, de los que $€ 2200$ millones fueron para proyectos fuera de la UE.

La UE se ha comprometido a destinar al menos un 20\% (unos $€ 12000$ millones) de su ayuda externa a la financiación de acciones climáticas de relevancia entre el periodo 20142020, lo que implica que doblará con creces el presupuesto destinado a esta área con respecto al periodo 2007-2013. A esto hay que sumarle las aportaciones del BEI, que serán de alrededor de los €2 000 millones anuales solo para los países en desarrollo y exclusivos para proyectos climáticos.

Para dar ayuda técnica y mejorar las capacidades en países en desarrollo, la UE tiene programas bilaterales y multilaterales que van desde las plataformas de diálogo hasta la elaboración de políticas climáticas en el sector forestal. Por ejemplo, tiene el programa Euro Clima, que incluye a 18 países de Latinoamérica y que tiene un presupuesto de $€ 15$ millones para el periodo 2009-2016; el proyecto Clima East, que apoya a los países del Este con $€ 18$ millones, y el Clima South Project, que tiene un presupuesto de $€ 5$ millones para los países del norte de África y Oriente Próximo (2013-2016) (ver anexo I).

Además de estos programas, la UE ha puesto en marcha otros instrumentos para movilizar recursos adicionales, en este caso intentando movilizar la inversión privada. Así, tiene instrumentos como el GEEREF (Global Energy Efficiency and Renewable Energy Fund), que pretende financiar proyectos relacionados con el medioambiente a partes iguales entre la UE y la inversión privada. Hasta la fecha se han aprobado proyectos en el África Subsahariana, Asia, Latinoamérica y Caribe por un importe de unos €5 000 millones. (Ver anexo II).

\footnotetext{
${ }^{44}$ Consejo de la Unión Europea: EU submission 2014 on strategies and approaches for scaling up climate finance, septiembre 2014, p. 4.
} 
Otro instrumento de este tipo es el Proyecto NAMA (Nationally Appropriate Mitigation Actions), iniciativa germano-británica en el que también colaboran Dinamarca y la Comisión Europea, y que actualmente está financiando nueve proyectos en países como Chile, México, Costa Rica, Indonesia, Perú, Tailandia o Burkina Faso. (Ver anexo III).

Además de las iniciativas anteriores, la UE ha movilizado entre 2007 y 2014 alrededor de $€ 300$ millones en créditos a través de la Global Climate Change Alliance (GCCA), destinada a los países más vulnerables, como Chad, Malawi o algunas islas AOSIS. O iniciativas como la $E U$ REDD Facility, centrada en la degradación forestal, o los apoyos a la Low-emission Capacity Building Programme y el Partnership for Market Readiness, implementados por el PNUD y el Banco Mundial respectivamente.

2.3.3. En Cancún se expresa la necesidad de que los países desarrollados reduzcan sus emisiones entre un 25-40\% por debajo de los niveles de 1990 para 2020.

En 2012 la UE había conseguido reducir un 18\% las emisiones con respecto a 1990. Un dato muy relevante que señala la UE es la relación entre reducción de emisiones y la mejora de la economía. Así, el PIB europeo aumentó un 1.4\% entre 2010 y 2011 a la vez que las emisiones caían un $3.3 \%$ en el mismo periodo ${ }^{45}$. Esa relación entre la reducción de emisiones e incremento de PIB también se da en periodos más largos; entre 1990-2012, el PIB de la eurozona aumentó en su conjunto un $45 \%$, a la vez que las emisiones caían un $19 \%{ }^{46}$. Este dato es importante a la hora de explicar las posibilidades de crecimiento económico derivadas de las inversiones en tecnologías más respetuosas con el medioambiente y a la hora de convencer a aquellos actores que relacionan la lucha contra el cambio climático con la ralentización de la economía.

La Comisión Europea tiene entre sus objetivos prioritarios la energía, el clima, el empleo y el crecimiento. Todo ello va de la mano y parece que el plan de la UE es apostar por una reforma económica más sostenible con el medioambiente y por la generación de empleo en el área de las nuevas energías. El 20\% del presupuesto europeo está destinado al cambio climático y un $35 \%$ del presupuesto destinado a ciencia e investigación es para el área de la innovación climática ${ }^{47}$. De hecho, buena parte de los fondos del programa Horizon 2020 están destinados a la investigación sobre las consecuencias que el cambio climático tendrá en la seguridad europea. Y todo ello refuerza la idea de que la UE tiene que hacer una reconversión industrial hacia una economía más verde y sostenible.

De la mano del trabajo para ralentizar el cambio climático están las grandes inversiones que la UE realiza en energías renovables. Actualmente, la UE es el mayor importador de energía mundial, lo que le supone unos 400000 millones de euros anuales ${ }^{48}$. Si bien la apuesta actual parece ser incrementar el gas proveniente del norte de África (la Unión ha identificado tres corredores de energía estratégicos que reforzarán su interconexión energética $^{49}$ ), lo cierto es que esta es una zona potencialmente inestable debido a la expansión del terrorismo islámico. Por ejemplo, el Plan Solar del Mediterráneo, aprobado en la reunión de la Unión por el Mediterráneo de julio de 2008 en París, muestra el interés de la Unión por desarrollar las energías renovables en el sur del Mediterráneo, pero hasta el momento solo ha

\footnotetext{
45 Jos Delbeke: Challenges and opportunities of low carbon development and building resilience. European Commission - DG Clima,en http://ufmsecretariat.org/wp-content/uploads/2014/05/DG-Clima-Challenges-andopportunities-of-low-carbon-development-and-building-resilience.pdf

${ }^{46}$ Comisión Europea: Progress towards achieving the Kyoto and EU 2020 objectives, octubre 2014, p. 7.

${ }^{47}$ Horizon 2020 Projects: Climate Change Action. Issue five (2015) en http://horizon2020projects.com/wpcontent/uploads/2015/01/2 H5-C-Hedegaard-2007_Special_atl.pdf

${ }^{48}$ Íbid.

${ }^{49}$ Ver trabajo de Soledad Segoviano sobre la nueva agenda de seguridad energética de la UE en el Mediterráneo, en este mismo número de la revista UNISCI.
} 
puesto en marcha pequeños proyectos de asistencia técnica y de intercambio de información en esa área. La escasa velocidad a la que progresan los proyectos europeos en la otra orilla del Mediterráneo muestra lo difícil que es abrir una línea de abastecimiento energético cuando no existe un mínimo de seguridad que garantice las inversiones en proyectos energéticos. La crisis en Ucrania no ha hecho sino confirmar a la UE que hay que apostar por nuevas energías para ser más independiente y por tanto poder tener un mayor margen de negociación con terceros estados. No obstante, la falta de seguridad no siempre permitirá elegir al suministrador de energía en cada momento, por lo que quizá sería conveniente reflexionar sobre la necesidad de aumentar la inversión en energías renovables dentro del propio territorio de la Unión a fin de reducir la dependencia de la energía exterior, cuyo suministro está supeditado a la seguridad o a la voluntad de los gobernantes de exportar esa energía al territorio europeo.

Además de las consecuencias positivas que los compromisos europeos tendrán sobre la economía (a medio y largo plazo) y el medioambiente en general, este compromiso puede entenderse como una apuesta de la UE para ser más independiente en el mundo de las relaciones internacionales $\mathrm{y}$, sobre todo, más independiente de los hidrocarburos de terceros países.

\section{Instrumentos de Cooperación en el Mediterráneo. ¿Actor clave o irrelevante?}

La Unión Europea tiene distintos instrumentos cooperación con el Magreb, su frontera en el Mediterráneo. No solo le interesa a la UE un Magreb estable, económica, social y políticamente, sino también un Magreb concienciado con las amenazas del medioambiente como el cambio climático, la escasez de agua o la desertificación, y que a su vez pueda garantizar la seguridad energética de la UE.

El sur del Mediterráneo es considerado una de las zonas donde más se van a notar los efectos del cambio climático, tanto en costes medioambientales como en costes sociales y humanos. Además de la pérdida de biodiversidad, el aumento de sequías o las inundaciones por el aumento del nivel del mar, esta zona del Mediterráneo deberá hacer frente al aumento de enfermedades, el desplazamiento de población, aumento de conflictos, aumento de la pobreza y la disminución de la calidad de vida ${ }^{50}$. Todo ello tiene un efecto claro sobre la seguridad de los países más vulnerables y, por su cercanía con la Unión Europea, también tendrá un impacto directo en la seguridad de la eurozona, principalmente con el aumento de los 1lamados «refugiados medioambientales» ${ }^{51}$.

En su Comunicación Conjunta al Parlamento Europeo en $2012^{52}$, la Comisión Europea identifica una serie de desafíos en la región del Magreb. Además de las reformas democráticas, socio-económicas y amenazas como el terrorismo y el crimen internacional, la Comunicación señala el medioambiente y el cambio climático entre los principales desafíos en la región. En esta comunicación, la Comisión relaciona el desempleo con la falta de

\footnotetext{
${ }^{50}$ Para más detalles sobre los impactos del cambio climático en el norte de África, ver Radhouane, Leila: "Climate change impacts on North African countries and on some Tunisian economic sectors". Journal of Agriculture and Environment Development, 107 (1), (2013), pp. 101-113.

${ }^{51}$ Ver el trabajo de Carlos del Río y Mónica Miranzo en este mismo número de la revista UNISCI para un análisis pormenorizado del impacto del cambio climático en el sur del Mediterráneo.

${ }^{52}$ Comisión Europea: Supporting closer cooperation and regional integration in the Maghreb: Algeria, Libya, Mauritania, Morocco and Tunisia. Joint Communication to the European Parliament, the Council, the European Economic and Social Committee and the Committee of the Regions. JOIN(2012)36 final,17 de diciembre de 2012.
} 
educación y formación, con la debilidad del sector privado, con la migración y con sectores clave en la región el medioambiente o la energía. Hay que tener en cuenta, además, que la población sigue aumentando en los países en desarrollo y, en consecuencia, también los niveles de consumo. Esto llevará inexorablemente a un aumento del consumo energético, lo que endurecerá los efectos del cambio climático. Las proyecciones hablan del aumento de la energía en un $50 \%$ de aquí a 2030, proviniendo más del $70 \%$ de ese aumento de los países en desarrollo $^{53}$. Todo esto hace más que nunca necesaria la transferencia de tecnología por parte de los países desarrollados y el aumento del número de iniciativas en los países del Sur que aumenten la producción de energías renovables, lo que a su vez conducirá a la disminución del cada vez mayor consumo de energía fósil en estos países.

Entre los programas que tiene la Unión Europea en marcha, encontramos el Horizon 2020, que tiene entre sus objetivos desarrollar iniciativas de investigación conjunta para abordar temas como la salud, la energía, el medioambiente, la seguridad alimentaria y la escasez de agua. Los tres sectores clave de los proyectos Horizon 2020 para el Sur de Mediterráneo son la gestión de aguas residuales y de residuos, las emisiones y la descontaminación del Mediterráneo.

También está interesada la UE en que haya en el Magreb un mercado integrado en el área de la energía que dé mayor seguridad a ese mercado, algo de lo que se podría beneficiar la UE y que a su vez serviría para crear más empleo y mejorar indirectamente el medioambiente ${ }^{54}$. Un Magreb fuerte económica y políticamente también será un Magreb capaz de luchar en mejores condiciones y de forma más eficaz contra los desafíos medioambientales y contra el cambio climático en particular.

Un Magreb que actúa contra el cambio climático es beneficioso para la Unión Europea, tanto por las posibilidades de negocio para sus empresas, como por la propia generación de riqueza en los países del Magreb derivados de las mejoras en la utilización de recursos, lo que beneficiaría de forma indirecta a los países europeos en forma de menos migraciones y mejor conservación del medioambiente en general y del Mediterráneo en particular. Esto supone no solo un compromiso por mejorar la economía a uno y otro lado del Mediterráneo, sino también incidir en la mejora de la seguridad desde un punto de vista holístico, tanto en su vertiente social, sanitaria y alimentaria (por ejemplo con el aumento de la producción de las tierras), como en su vertiente más física (disminuyendo la necesidad de emigrar ante la mejora de la economía local y disminuyendo, por tanto, el número de inmigrantes climáticos que llegan al territorio europeo).

La Comisión reconoce en su Comunicación la necesidad de enfrentar los problemas medioambientales de forma conjunta, incluyendo asuntos como el agua, la atmósfera, el medio marino, el suelo y la biodiversidad ${ }^{55}$. Y a pesar de reconocer que la región ya está sufriendo las consecuencias del cambio climático en sectores clave de la economía como la agricultura, el turismo y los precios de los alimentos, también ve una oportunidad en ese escenario si comienza a virar hacia un espacio geográfico donde las energías renovables y eficientes tengan mayor protagonismo. Ciertamente, el Magreb está bien situado para poder desarrollar proyectos conjuntos que aprovechen la tecnología y el conocimiento europeo, y aprovechen el sol y el viento de la zona.

\footnotetext{
${ }^{53}$ Yábar Sterling, Ana: "IPCC Assessment Reports: Challenges Presented", p. 28, en Marquina, Antonio (ed) (2010): Global Warming and Climate Change. Prospects and Policies in Asia and Europe. New York, Palgrave Macmillan.

${ }^{54}$ Comisión Europea: Supporting closer cooperation..., op. cit, pp. 12-13.

${ }^{5}$ Íbid., p. 5.
} 
No hay duda de que estas inversiones, que serían bienvenidas en cualquiera de los países del Magreb y que históricamente han sido reclamadas por los países del Sur, fomentarían la creación de empleo y las inversiones en general. Sin embargo, toda inversión privada proveniente de la Unión Europea dependerá de la estabilidad en el Magreb. Cualquier inversión económica que se realice deberá hacerse bajo unas condiciones mínimas de seguridad (incluyendo la seguridad jurídica) para así garantizar la viabilidad de inversiones y la continuidad de los proyectos a medio y largo plazo. La amenaza de organizaciones terroristas como el DAESH/Estado Islámico es ya una realidad en los países del Magreb, por lo que las inversiones deberán ir de la mano de un mayor compromiso europeo para estabilizar la zona. O, dicho de otro modo, no habrá inversiones significativas para detener el cambio climático si primero no hay estabilidad, y aunque esta condición se cumple en todos los casos, se aplica especialmente a la inversión privada.

\subsection{Unión para el Mediterráneo (UfM)}

Para poder evaluar el peso que tienen las inversiones de la Unión Europea en el sur del Mediterráneo, podemos analizar, por un lado, el número de proyectos e iniciativas de la UE en esta región; y por otro, el peso de las inversiones en el área.

Uno de los instrumentos clave que tiene la UE en el Mediterráneo para combatir el cambio climático es la Unión para el Mediterráneo. Creada en 2008, tiene como objetivo aumentar la integración regional y la cohesión entre los países euromediterráneos y promover la paz, la democracia, la cooperación y la prosperidad en la región. Sin duda, es la iniciativa de cooperación con el sur del Mediterráneo más importante y dinámica hasta el momento. En el área del cambio climático y el medioambiente en general, se ha limitado principalmente a poner en marcha programas de intercambio de información y de capacitación para, por ejemplo, la mejora de la calidad y la gestión de las aguas en los países MENA.

En la Reunión Ministerial sobre Medioambiente y Cambio Climático de la UfM de mayo de 2014 en Atenas, se incluyó el cambio climático por primera vez como área prioritaria para la cooperación en la región. En la declaración de ese encuentro, se subrayó la urgencia de hacer frente al calentamiento global y su relación directa con problemas como la energía, la escasez de agua, la desertificación, la seguridad alimentaria, el consumo insostenible o la sobrepoblación ${ }^{56}$.

La Cumbre de Atenas es interesante porque ahí se aprueba uno de los pocos documentos en los que s señala la necesidad de adoptar nuevas políticas sobre producción y consumo responsables, una de las demandas tradicionales de los países del Sur a los del Norte en las negociaciones sobre cambio climático. Además, como resultado de esta reunión, se creó el Grupo de Expertos de la UfM para el Cambio Climático, con el objetivo de aumentar el dialogo regional e identificar y desarrollar proyectos e iniciativas tanto en el ámbito de la mitigación como de la adaptación al cambio climático. Aunque este grupo de expertos solo se ha reunido una vez (octubre de 2014), no deja de ser un paso más para que haya un intercambio de conocimientos en esta área.

Uno de los proyectos prioritarios para la Unión por el Mediterráneo es el Plan Solar del Mediterráneo, lanzado en 2008 en la cumbre de París, a la que asistían los Jefes de Estado de los países de la Unión Europea y de 16 países del Sur y el Este del Mediterráneo. El objetivo es poner en marcha proyectos que aumenten la capacidad de la energía renovable en $20 \mathrm{GW}$

\footnotetext{
${ }^{56}$ UfM: Declaration: Unión for the Mediterranean Ministerial Meeting on Environment and Climate Change, 13 mayo 2014.
} 
para el año 2020 a través de proyectos de trabajo común y de financiación ${ }^{57}$. Sin embargo, el Plan de Solar no ha dado ningún otro resultado más allá del documento acordado en 2008.

\subsection{Proyecto Clima South frente a otros proyectos de lucha contra el cambio climático}

Otro de los instrumentos importantes de la UE en el Mediterráneo es el proyecto Clima South, lanzado en 2013 con el objetivo de apoyar políticas contra la escasez de agua, los cambios de clima extremos y la desertificación, a la vez que mejoraba el crecimiento económico y el desarrollo sostenible.

Para conocer la relevancia del proyecto Clima South, hay que compararlo con otros proyectos similares, en este caso, el Euroclima y el proyecto Clima East. Como se ve en el anexo 1, la región a la que menos dinero dedica la UE para proyectos de lucha contra el cambio climático en términos absolutos es la región del Mediterráneo, siendo la mayor financiación anual para el Este de Europa. No obstante, para hacer una mejor valoración, deberíamos tener en cuenta el esfuerzo que hace la UE en función de la población de cada país. Siguiendo este indicador, encontramos entonces que el Este de Europa sigue siendo claramente la región en la que más invierte la UE, pero que la inversión per cápita es superior para el proyecto Clima South del Mediterráneo que para el programa Euro Clima de Latinoamérica. No obstante, en el caso del proyecto Clima South, los datos aportados son solamente cifras comprometidas, pero no necesariamente gastadas a fecha actual, por lo que habría que analizar cuál es el impacto de los proyectos llevados a cabo hasta el momento para valorar dónde pone la Unión Europea más interés.

Hasta el momento, Clima South se ha limitado a programas de intercambio de información a través de su página web, www.climasouth.eu, la creación de manuales con información genérica sobre el cambio climático ${ }^{58}$, y a la celebración de seminarios sobre adaptación o mejora de la gestión del riego, entre otros (hasta la fecha se han celebrado doce seminarios). Clima South está muy restringido al intercambio de información y al establecimiento de un diálogo entre las partes, intercambiando conocimientos sobre cómo poner en marcha políticas de ahorro energético, mejorar los sistemas de transporte, etc. Este es un paso más que necesario para establecer unos pilares sólidos que permitan desarrollar en el futuro proyectos de financiación y de intercambio de tecnología mucho más avanzados.

Euroclima (América Latina) tiene como principal objetivo reducir la pobreza mediante la reducción de la vulnerabilidad ambiental y social ante el cambio climático. Para ello se centra en el intercambio de información y experiencias, en la búsqueda e implementación de medidas de adaptación y mitigación y en el desarrollo de una agricultura sostenible ${ }^{59}$.

Entre los programas desarrollados a través de este instrumento están la mejora de información científica y del conocimiento sobre el impacto del cambio climático en América Latina. En 2013 se habían invertido $€ 5$ millones a través de este programa ${ }^{60}$. Entre 2014 y 2016 se prevé gastar $€ 11.4$ millones en proyectos relacionados con la mejora del diálogo entre países y en la identificación de casos piloto para implementar políticas de mitigación y

\footnotetext{
${ }^{57}$ UfM: Mediterranean Solar Plan: Joint Committee of National Experts discusses Draft of the Master Plan, 22 febrero de 2013. En http://ufmsecretariat.org/mediterranean-solar-plan-joint-committee-of-national-expertsdiscusses-draft-of-the-master-plan/ Y Neighbourhood Investmeng Facility (NIF). Summary Sheet Mediterranean Solar Plan Project Preparation Initiative MSP-PPI, en http://ufmsecretariat.org/wp-content/uploads/2013/01/MSP-PPI_brochure.pdf

${ }_{58}^{58}$ Clima South: Key developments in climate change policies. En http://www.climasouth.eu/drupal/en/node/241

${ }^{59}$ Euro Clima: La ciencia y la política unidas frente al cambio climático. 2010-2016, en http://www.euroclima.org/images/Publicaciones/LibrosEUROCLIMA/Brochure EUROCLIMAII web ES.pdf

${ }^{60}$ Euro Clima: Results of the First Phase. Science and Policy jointly fighting Climate Change. May 2010-May 2013, en http://euroclima.org/images/Publicaciones/LibrosEUROCLIMA/BookletEUROCLIMAResults_EN.pdf
} 
proyectos para una agricultura más sostenible que mejore la seguridad alimentaria y detenga el cambio climático.

El proyecto Clima East es sin duda el programa más ambicioso de cooperación regional para combatir el cambio climático. Está dividido en dos partes: 11 millones implementados a través del PNUD consistente en un número de proyectos piloto para minimizar las emisiones de fuentes fósiles y para ayudar a los ecosistemas a adaptarse al cambio climático; y una segunda parte, financiada con 7 millones de euros, que tiene como objetivo mejorar las políticas de cambio climático, las estrategias y mecanismos de mercado, así como un mayor intercambio de información y conocimientos ${ }^{61}$.

Como vemos, la financiación de la Unión Europea a través de instrumentos directos de financiación en el área del cambio climático en el Magreb está aún en un estado incipiente. Si bien se han movilizado los fondos necesarios para invertir en el sur del Mediterráneo, lo cierto es que hasta la fecha las iniciativas puestas en marcha tienen más que ver con el intercambio de información y de aumento de las capacidades de gestión en los países magrebíes que con grandes proyectos para mitigar y adaptarse al cambio climático en estos países.

Lo mismo puede decirse de las iniciativas privadas en las que participa y fomenta la Unión Europea. Por ejemplo, los instrumentos GEEREF y NAMA (anexos II y III) han sido esenciales para poner en marcha proyectos para mejorar el desarrollo urbano, aumentar el uso de energías renovables o preservar la biodiversidad; pero ninguno de esos proyectos de iniciativa privada se ha llevado a cabo en países del Magreb, lo que puede suceder bien por la ausencia de seguridad en la región, bien por la falta de mano de obra local suficientemente capacitada, por las pocas ventajas económicas que invertir en estos países puede traer para las empresas interesadas, o por un cúmulo de razones que sobrepasan el objeto de este análisis.

Lo que está claro es que, si bien hay un interés por parte de la Unión Europea en intercambiar experiencias y financiar proyectos, hasta ahora esos proyectos no se han materializado más allá de reuniones entre expertos de ambas orillas del Mediterráneo. Y aunque la financiación privada es imprescindible para que la industria alrededor de las energías limpias despegue y para que haya un trasvase de tecnología con la que mitigar y adaptarse a los efectos del cambio climático, esa iniciativa privada no llegará en ningún caso a todos los estados y deberán ser las instituciones las que sigan invirtiendo en los países en desarrollo independientemente de la rentabilidad económica para las arcas públicas.

\section{Conclusiones}

¿Es la Unión Europea un actor clave en las negociaciones sobre cambio climático? La respuesta a esta primera pregunta que nos hacíamos es que, sin duda, la UE es un actor necesario y con un innegable liderazgo en el régimen internacional del medioambiente. La Unión es un actor que ha cumplido con sus objetivos y sus compromisos por encima del resto de países; sigue fijándose los objetivos de reducciones a niveles de 1990 y no a niveles más reciente como hacen Estados Unidos o Canadá; ha contribuido con su parte en los instrumentos de financiación y está más que dispuesto a colaborar con el Fondo Verde. También vemos que la UE ha tendido durante los últimos años a marcar el camino actuando y dando ejemplo al resto de la comunidad internacional, proponiendo textos y presionando al resto de países para que fueran también activos. Sin embargo, la Unión Europea no tiene el poder necesario para conseguir que el resto de países se muevan al mismo ritmo que ella. La UE es un actor aventajado al que muchos querrían copiar, pero no es el líder que consigue

\footnotetext{
${ }^{61}$ Clima East: http://www.climaeast.eu/
} 
arrastrar y movilizar al resto de estados. China y Estados Unidos, menos comprometidos históricamente con el cambio climático, seguirán siendo protagonistas en París; eso sí, nada conseguirán sin el apoyo de la Unión Europea y de países emergentes como AILAC.

Lo positivo en París será que todos los países (desarrollados o en desarrollo, del Norte o del Sur) firmen algo, independientemente de que los objetivos sean más o menos ambiciosos. A esta cumbre todos llegarán con la esperanza de firmar un acuerdo definitivo que reemplace el Protocolo de Kioto, pero también sabiendo que habrá muchas asuntos espinosos que resolver, porque en París el objetivo no es firmar un nuevo tratado para luchar contra el calentamiento global, sino que detrás hay una serie de consecuencias importantes para el modelo económico e industrial actual y para el desarrollo sostenible de nuestras sociedades. Vincularse a la reducción de gases de efecto invernadero es también vincularse a un cambio profundo en las economías nacionales, un paso que no todos los actores internacionales están dispuestos a dar a no ser que haya un compromiso por parte de todas y cada una de las grandes economías.

A diferencia de lo que pasó en Copenhague, que dejaron para el final de las negociaciones los aspectos más espinosos, la Unión Europea está haciendo grandes esfuerzos para que se llegue a París con unos compromisos de reducción por parte de cada uno de los Estados. Esto, en principio, haría que ya hubiera de antemano una posición sólida y que las discusiones se centren en otros temas igual de espinosos, como la financiación y la transferencia de tecnología, ambos de suma importancia para que los países más vulnerables puedan cumplir con los compromisos que han presentado y que en muchos casos son condicionados a la recepción de recursos financieros y tecnológicos por parte de los países desarrollados. Encontrar mecanismos claros y transparentes sobre quién financia, a quién, cuánto y cuándo - todo ello respetando el innegociable principio de responsabilidades comunes pero diferenciadas-, será clave para que de París surja un tratado que realmente marque la diferencia con respecto a todas las cumbres anteriores.

La Secretaria Ejecutiva de la CMNUUCC, Christiana Figueres, reconocía recientemente que en París será difícil resolver el problema del cambio climático de un día para otro y que no creía posible que se lograra el objetivo de limitar el aumento de la temperatura a dos grados centígrados con respecto a niveles preindustriales ${ }^{62}$. Sin embargo, hay cabida para la esperanza en París. En su reunión en Elmau (Alemania) el 8 de junio de 2015, los países del G7, Estados Unidos, Alemania, Reino Unido, Francia, Italia, Japón y Canadá, que, recordemos, son grandes emisores industrializados, han alcanzado el compromiso de no sobrepasar esos dos grados centígrados críticos y para ello están dispuestos a reducir sus emisiones entre un 40 y un $70 \%$ para 2050 con respecto a 2010. Además, se han mostrado dispuestos a impulsar el Fondo Verde del Clima a partir de $2020^{63}$.

A estas buenas noticias hay que sumarles lo que parece ser una muestra de que las principales industrias petroleras europeas están dispuestas a unirse a la lucha para detener el aumento de la temperatura global ${ }^{64}$, lo que hay que interpretar como un paso muy positivo, pues las empresas privadas son clave para detener las emisiones.

En línea con lo anterior, el propio FMI ha admitido que los subsidios a las empresas fósiles, calculados en un $\$ 5.3$ billones (un 6.5\% del PIB global), tiene efectos perversos para

\footnotetext{
62 "Los subsidios a las energías fósiles no tienen ningún sentido", El País, 28 mayo 2015.

${ }^{63}$ The White House: G-7 Leaders' Declaration. Schloss Elmau, Alemania, (8 junio 2015), en https://www.whitehouse.gov/the-press-office/2015/06/08/g-7-leaders-declaration

${ }^{64}$ Financial Times: European energy groups seek UN backing for carbon pricing system, (31 mayo 2015), en http://www.ft.com/intl/cms/s/0/2fc5662e-0643-11e5-b676-00144feabdc0.html\#axzz3cYNVwNOS
} 
la economía, el crecimiento, el cambio climático y la desigualdad ${ }^{65}$. Es posible que algo esté cambiando.

¿Qué instrumentos de cooperación tiene la Unión Europea en el Magreb para mejorar la lucha contra el cambio climático? En este documento hemos visto que existen distintos instrumentos de cooperación de la Unión Europea con el Mediterráneo — cargados habitualmente de cierta retórica triunfalista-, pero que hasta la fecha se han quedado relegados al intercambio de información entre países. En cuanto a las inversiones privadas, priorizadas por la Unión, vemos que no son la solución en casos donde la rentabilidad económica para la industria, como en el área del Magreb, no es obvia.

${ }^{65}$ IMF Direct: Act Local, Solve Global: The \$5.3 Trillion Energy Subsidy Program, (18 mayo 2015), en http://blog-imfdirect.imf.org/2015/05/18/act-local-solve-global-the-5-3-trillion-energy-subsidy-problem/ 


\section{Anexo I}

Comparación esfuerzo de la UE en cada uno de los programas de cooperación para combatir el cambio climático ${ }^{1}$

\begin{tabular}{|c|c|c|c|c|}
\hline NOMBRE & $\begin{array}{l}\text { MILLONES DE } \\
\text { EUROS/AÑO }\end{array}$ & DESTINATARIOS & $\begin{array}{c}\mathbf{N}^{0} \text { TOTAL } \\
\text { HABITANTES }^{2}\end{array}$ & $\begin{array}{c}€ \text { PER } \\
\text { CÁPITA }\end{array}$ \\
\hline $\begin{array}{c}\text { PROYECTO } \\
\text { CLIMA SOUTH } \\
(2013-2016)\end{array}$ & $\begin{array}{l}€ 1.25 \text { millones } \\
\text { (Total: €5m.) }\end{array}$ & $\begin{array}{l}9 \text { países: Argelia, } \\
\text { Egipto, Israel, } \\
\text { Jordania, Líbano, } \\
\text { Libia, Marruecos, } \\
\text { Palestina, Túnez }\end{array}$ & 194.2 & $0.00643 /$ año \\
\hline $\begin{array}{c}\text { PROGRAMA } \\
\text { EURO CLIMA } \\
(2009-2016)\end{array}$ & $\begin{array}{l}€ 1.87 \text { millones } \\
\text { (Total: } € 15 \mathrm{~m} . \text { ) }\end{array}$ & $\begin{array}{l}18 \text { países: Argentina, } \\
\text { Bolivia, Brasil, Chile, } \\
\text { Colombia, Costa Rica, } \\
\text { Cuba, Ecuador, El } \\
\text { Salvador, Guatemala, } \\
\text { Honduras, México, } \\
\text { Nicaragua, Panamá, } \\
\text { Paraguay, Perú, } \\
\text { Uruguay, Venezuela. }\end{array}$ & 582.6 & $0.00320 /$ año \\
\hline $\begin{array}{c}\text { PROYECTO } \\
\text { CLIMA EAST } \\
(2012-2016)\end{array}$ & $\begin{array}{l}€ 3.6 \text { millones } \\
\text { (Total: } € 18 \mathrm{~m} . \text { ) }\end{array}$ & $\begin{array}{l}7 \text { países: Armenia, } \\
\text { Azerbayán, } \\
\text { Bielorrusia, Georgia, } \\
\text { Moldavia, Rusia, } \\
\text { Ucrania. }\end{array}$ & 218.4 & $0.01650 /$ año \\
\hline
\end{tabular}

\footnotetext{
${ }^{1}$ EU submission 2014 strategies and approaches for scaling up climate finance.

${ }^{2}$ Fuente: Banco Mundial. Datos de población en 2013 (millones de habitantes). http://datos.bancomundial.org/indicador/SP.POP.TOTL Datos sobre población de Palestina del Ministerio de Exteriores de España: Oficina de Información Diplomática. Ficha País Territorios Palestinos.
} 


\section{Anexo II}

Instrumentos en los que participa la UE para estimular la financiación privada en proyectos relacionados con el cambio climático (GEEREF)

\begin{tabular}{|l|l|l|}
\hline \multicolumn{1}{|c|}{ GEEREF } \\
\hline REGIÓN & PAÍSES & INVERSIÓN \\
\hline SUDESTE ASIÁTICO & Vietnam, Filipinas, Indonesia, Tailandia & $€ 10 \mathrm{~m}$. \\
\hline ÁFRICA & Kenia, Ruanda, Sudáfrica, Tanzania, Uganda & $€ 10 \mathrm{~m}$. \\
\hline LATINOAMÉRICA & Brasil, México, Perú, Chile, Colombia. & $€ 12.5 \mathrm{~m}$. \\
\hline SUDÁFRICA & Zaire & $€ 10 \mathrm{~m}$. \\
\hline LATAM y CARIBE & Colombia, México, Centro América y Caribe. & \\
\hline SUDESTE ASIÁTICO & $\begin{array}{l}\text { Bangladesh, Sri Lanka, Indonesia Tailandia, Vietnam, } \\
\text { Malasia }\end{array}$ & $€ 12.5 \mathrm{~m}$. \\
\hline
\end{tabular}




\section{Anexo III}

Instrumentos en los que participa la UE para estimular la financiación privada en proyectos relacionados con el cambio climático (NAMA Facility)

\begin{tabular}{|c|c|c|}
\hline \multicolumn{3}{|c|}{ NAMA FACILITY } \\
\hline PAÍSES & INVERSIÓN & ÁREA \\
\hline Tailandia & $€ 14.7 \mathrm{~m}$ & Refrigeración y aire acondicionado \\
\hline Tayikistán & $€ 13 \mathrm{~m}$ & Sector forestal, conservación biodiversidad \\
\hline Perú & $€ 9 \mathrm{~m}$ & Transporte urbano \\
\hline México & $€ 14 \mathrm{~m}$ & Aumentar eficiencia en sector construcción \\
\hline Indonesia & $€ 14 \mathrm{~m}$ & Transporte urbano \\
\hline Costa Rica & $€ 7 \mathrm{~m}$ & Reducción emisiones en plantaciones café \\
\hline Colombia & $€ 14.9 \mathrm{~m}$ & $\begin{array}{l}\text { Planificación y desarrollo urbano (gestión de tráfico en } \\
\text { ciudades) }\end{array}$ \\
\hline Chile & $€ 15 \mathrm{~m}$ & Promoción energías renovables en PYMES \\
\hline Burkina Faso & $€ 13.5 \mathrm{~m}$ & Biomasa \\
\hline
\end{tabular}

